\title{
The road map for the seismic geotechnical vulnerability of the physical environment
}

\author{
S. Grasso \& M. Maugeri \\ Department of Civil and Environmental Engineering, Italy
}

\begin{abstract}
The increasing importance attributed to microzonation derives from the spatial variability of ground motion due to particular local conditions, from landslides and ground liquefaction noticed during recent earthquakes and from the awareness that many towns run a high risk because of the geotechnical characteristics of the foundations of structures. The Mediterranean area is characterised by a medium-high level of seismic risk, so earthquakes are a major cause of the destruction of monuments, residential and industrial buildings. Among the effects on the stability of the physical environment, landslides and liquefaction represent the most significant factors of vulnerability of the physical environment itself. Landslides are particularly relevant because they can deeply modify the physical environment and consequently they represent an aggravation factor for the vulnerability of buildings resting on a potentially landsliding slope. Microzonation of slope stability is then preliminary to the evaluation of the vulnerability of buildings. Vulnerability of the physical environment, related to the presence of cavities and to seismic induced landslides and liquefaction, has been analysed with special reference to the new modelling of such phenomena and to the application of the models to given areas. This paper deals with the vulnerability of the physical environment (landslides, liquefaction etc.), while the road map continues with the analysis of the vulnerability of monuments and buildings, with the aim of the estimation of the seismic resistance required to defend against seismic action given by the scenario earthquakes.
\end{abstract}

Keywords: road map, seismic geotechnical vulnerability, physical environment.

\section{Introduction}

For the characterisation of the expected ground motion and the evaluation of site effects and vulnerability of the physical environment the research activities and 
goals to be achieved are reported in the following. The main goals for the characterisation of the expected ground motion and site effects have been: source modelling of the Scenario Earthquake; detailed geological survey and geological mapping of the urban areas; noise measurements; site effects evaluation; synthetic accelerograms at the surface and at a given depth (bedrock).

The main goals for the vulnerability of the physical environment have been: test sites including borings located at the relevant sites; in situ tests performed inside boreholes, undisturbed sampling and laboratory tests in the dynamic field for detecting soil non-linearity behaviour; updating soil dynamic parameters and geotechnical mapping, including all borings, all geophysical measurements and all in situ and laboratory test results; seismic microzonation of the urban areas, the vulnerability of slopes to the Scenario Earthquake and application of the model to the landslide behaviour, located in the urban areas; modelling of liquefaction including instability due to lateral spreading; evaluation of soilstructure-interaction; survey of the cavities and implementation of a database of detected cavities; road infrastructures vulnerability, including evaluation of seismic instability of slopes, embankments and retaining walls, which can cause interruptions on the road system; urban system vulnerability evaluation.

Although the analysis of the vulnerability and seismic structural improvement of buildings to prevent damage are outside of the aim of this paper, the main goals to be achieved by the road map for seismic risk analysis are: assessment of the construction typology, identification tests and evaluation of vulnerability and earthquake resistance of monumental buildings; evaluation of building vulnerability and earthquake resistance for the most common construction typology of R.C. buildings; evaluation of critical acceleration for limiting state serviceability vulnerability for the most common construction typology of R.C. buildings; remedial works for the most common construction typology of R.C. buildings with traditional and innovative techniques; Code of Practice for the improvement of the most common typology of R.C. buildings; transfer of the Code of Practice to the Municipality and other Institution; transfer of the Code of Practice to the Engineers and to the Technicians; transfer to the Municipality office a Land Information System (LIS) database of all the results obtained by the Research Project; criteria for priority on the remedial works execution.

\section{Characterisation of the expected ground motion and site effects}

The main goal for the characterisation of earthquake sources has been the deterministic approach for modelling of the scenario earthquakes, while more often up to now the scenario earthquake is evaluated with a probabilistic approach, as reported by Cornell [1] for the San Francisco Bay Region, by the EERI committee on seismic risk for the Los Angeles area [2], by Das et al. [3] for North-East India, by Càceres Calix for Northern Central America [4] (Figures 1and 2) and by Shedlock [5] for North and Central America and the Caribbean (Figure 3). 


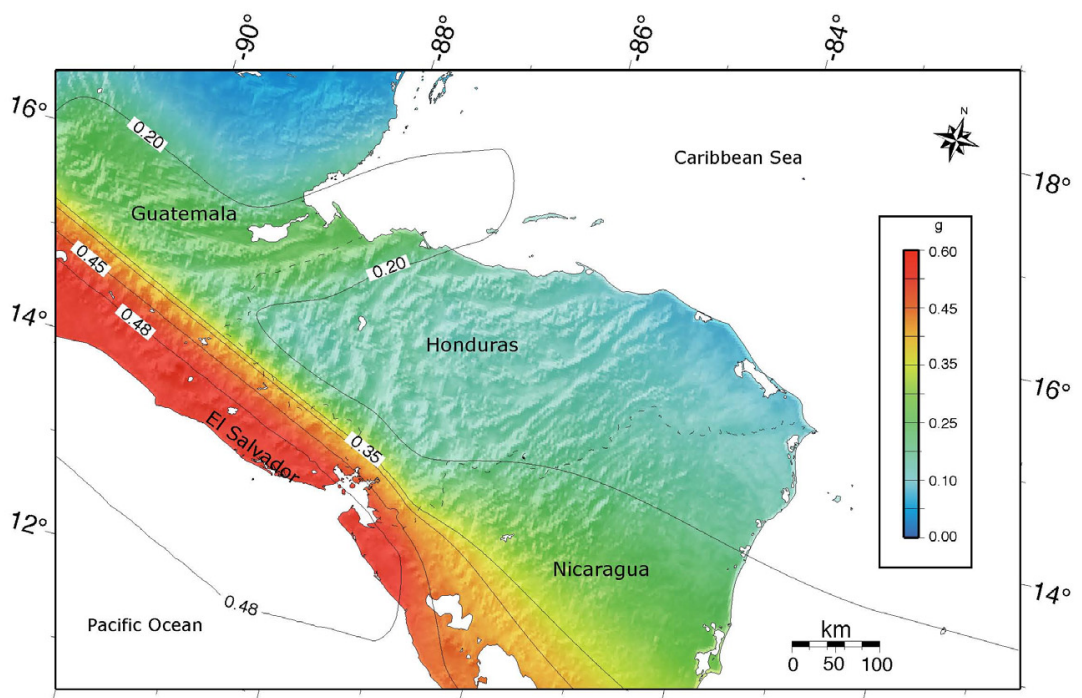

Figure 1: $\quad$ Seismic hazard map of Honduras for a return period of 100 years ( 0.4 probability of exceedance in 50 years), after Càceres Calix [4].
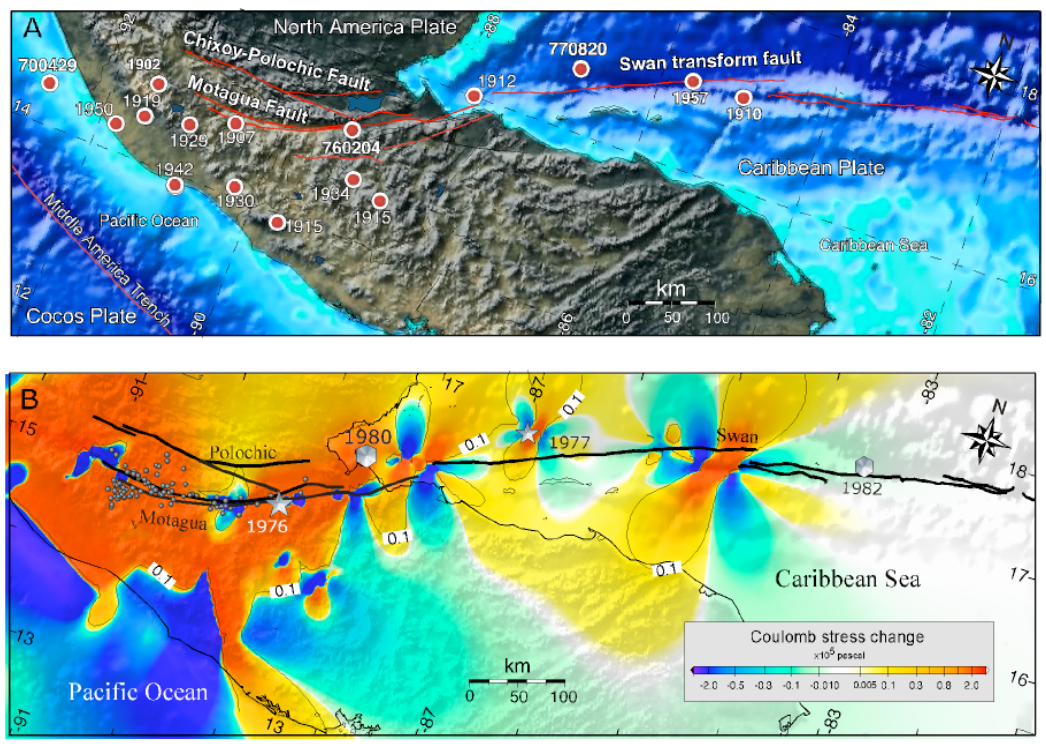

Figure 2: A: Earthquakes (filled circles) larger than $M_{w}=6$ for the period 1900-1977. B: Calculated Coulomb stress changes ( $\delta$ CFS) on optimally oriented strike slip faults, after Càceres Calix [4]. 


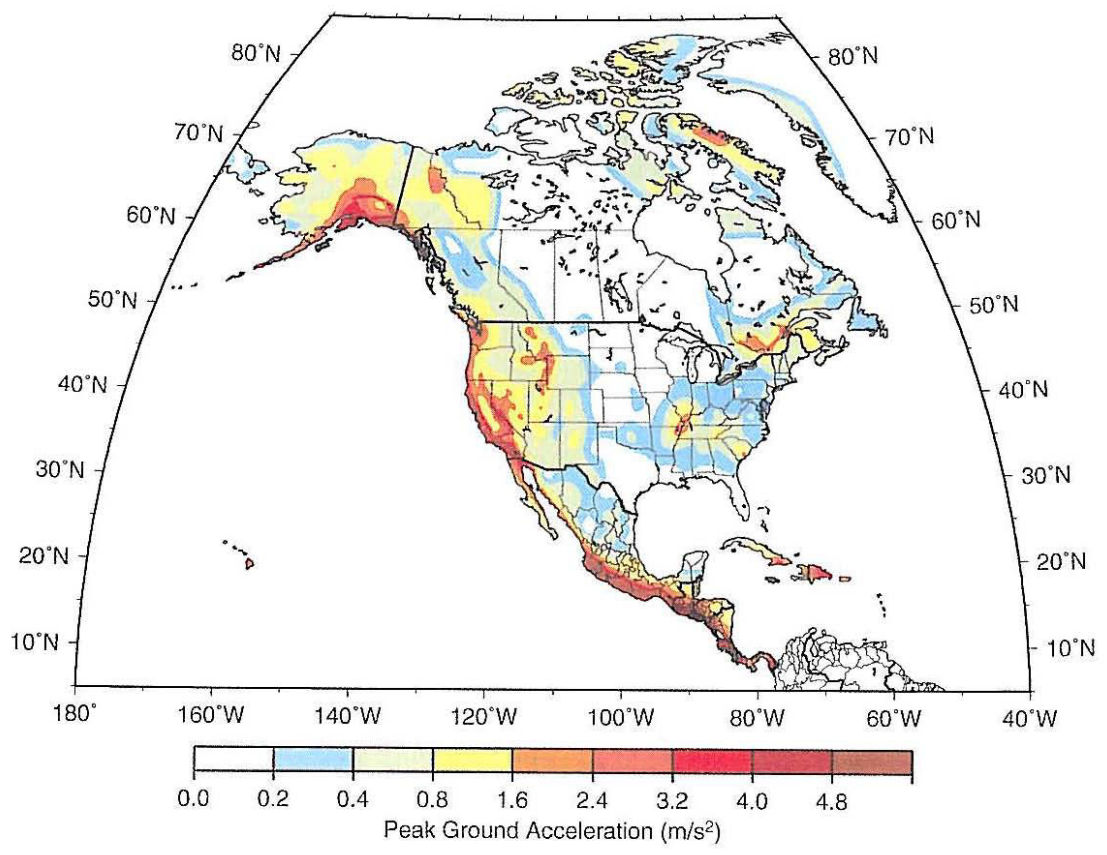

Figure 3: The seismic hazard map of North and Central America and the Caribbean (after Shedlock [5]).

The authors believe that the probabilistic approach could be used for seismic action evaluation over large areas, such as large countries (China, India, America, Caribbean, etc.) while the deterministic approach should be used for smaller areas, such as cities (San Francisco, Los Angeles, Catania, etc.).

Computation of the strong ground motion, as an example in Italy for the urban area of Catania, has been carried out for different earthquake scenarios. The results were that the Etna 1818 scenario earthquake with a magnitude $M=6.2$ appears to be the most critical one in the northern part of the city of Catania. This is somewhat surprising since the earthquake of 11 January 1693 is the largest one to have occurred in the region, and one commonly refers to it for hazard evaluation in Catania. However, the 1693 earthquake is the first level scenario earthquake and it is the most severe earthquake for the central and the southern part of the city of Catania. A third scenario earthquake is the Sicilian earthquake $(M=5.6)$, which occurred on December 13, 1990. This earthquake gives us the possibility of validating the road map for the evaluation of seismic risk comparing the results of the procedure with the damage caused by this medium-low level scenario earthquake. Site response analysis has been also performed using a 1-D model, as Catania is mainly a flat area with a very limited number of slopes. The 1-D method, which is commonly used in engineering practice, takes into account the detailed shear waves soil profile of surface layers, including soil non-linearity in the analyses. 


\section{Vulnerability of physical environment, road infrastructures and urban system}

Soil amplification of the ground motion given by seismic microzonation is an aggravation factor for the vulnerability of the physical environment and for buildings. Among the factors influencing the vulnerability of the physical environment, the potential landsliding areas and potential liquefiable areas must be considered. Physical knowledge of the land, and mainly of its geotechnical features, can be obtained through the use within GIS of borehole investigations with the chance to check their stratigraphic view through active links within the ArcView GIS. The location, as an example, of the 1200 geo-settled boreholes in the city of Catania is reported in Figure 4, together with the 5 geotechnical transepts. In some cases the boreholes can be accompanied by the results of the geotechnical in situ tests or laboratory tests. The determination of the dynamic characteristics of the soil can be obtained through precise tests performed in some test sites whose location can be also shown within GIS database Figure 5. By mixing the layers of the schematic geo-settled geological map of the urban areas with the layers of boreholes and geotechnical data, geo-settled geotechnical maps, based on shear wave velocity values of the soil, can be obtained (see Figure 6 for the Catania case).

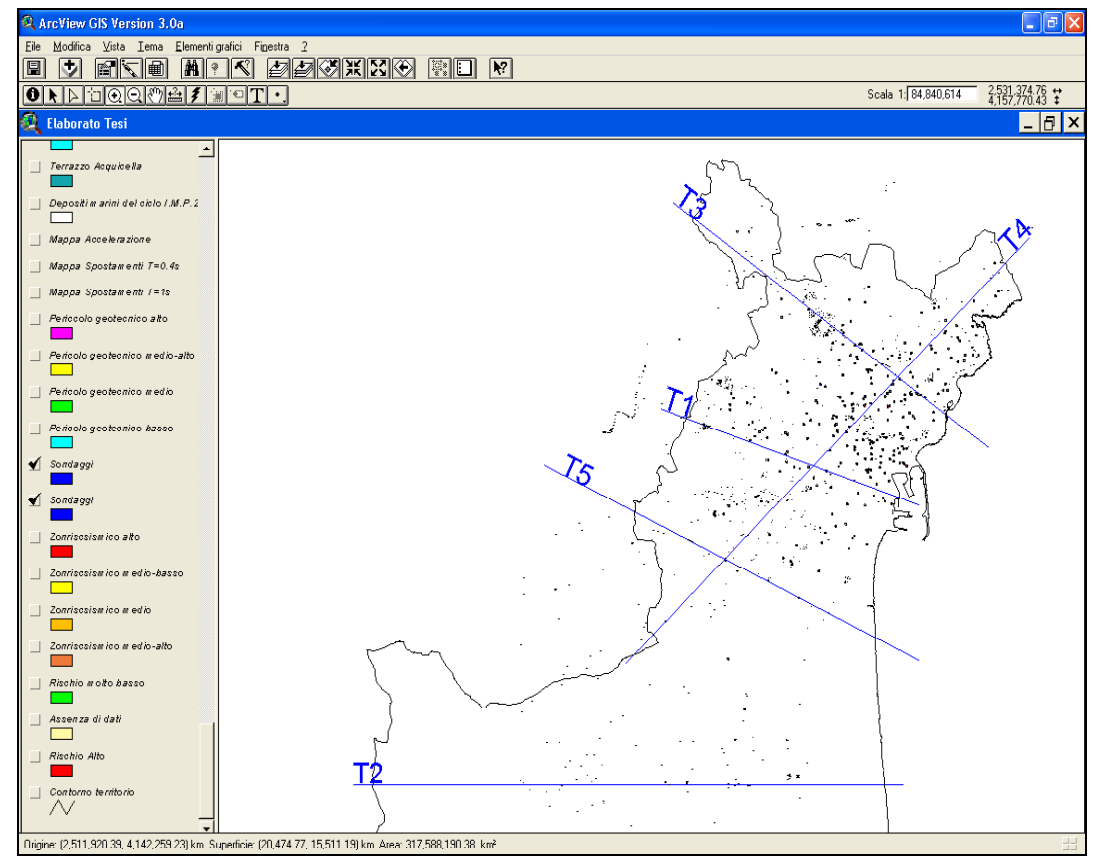

Figure 4: Location of the 1200 geo-settled borehole investigations within the ArcView GIS of the city of Catania. 


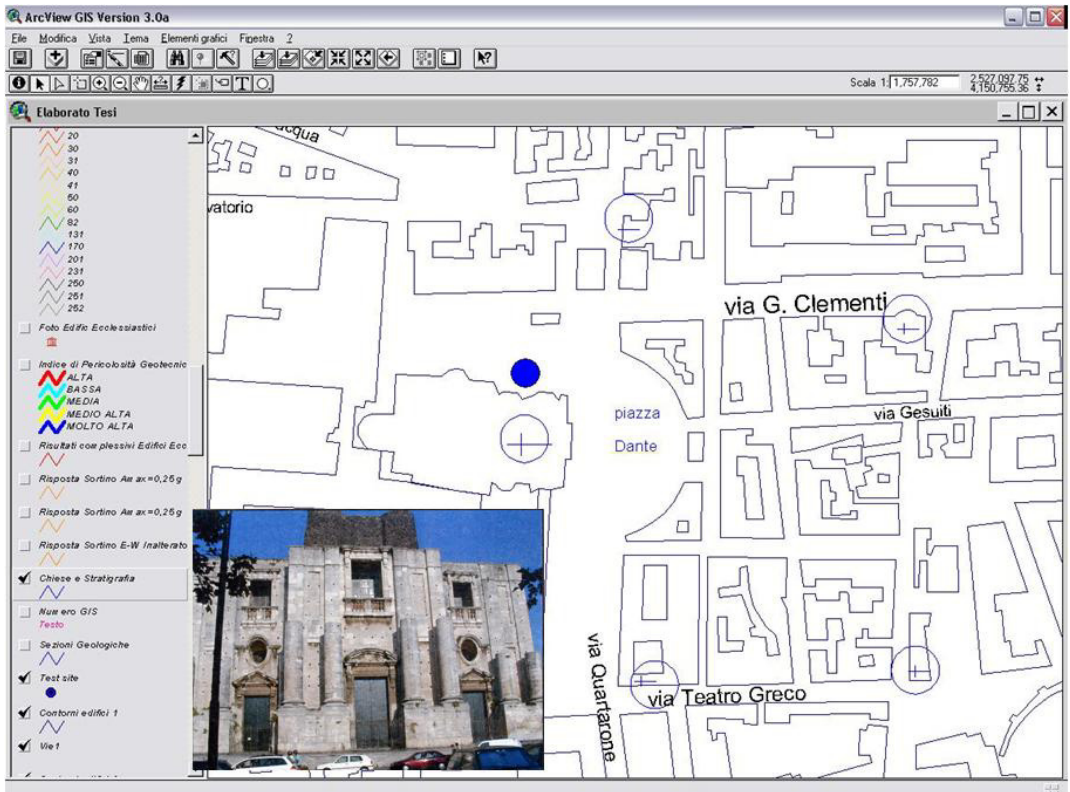

Figure 5: GIS location of the Saint Nicola alla Rena test site in the city of Catania including the location of the boring.

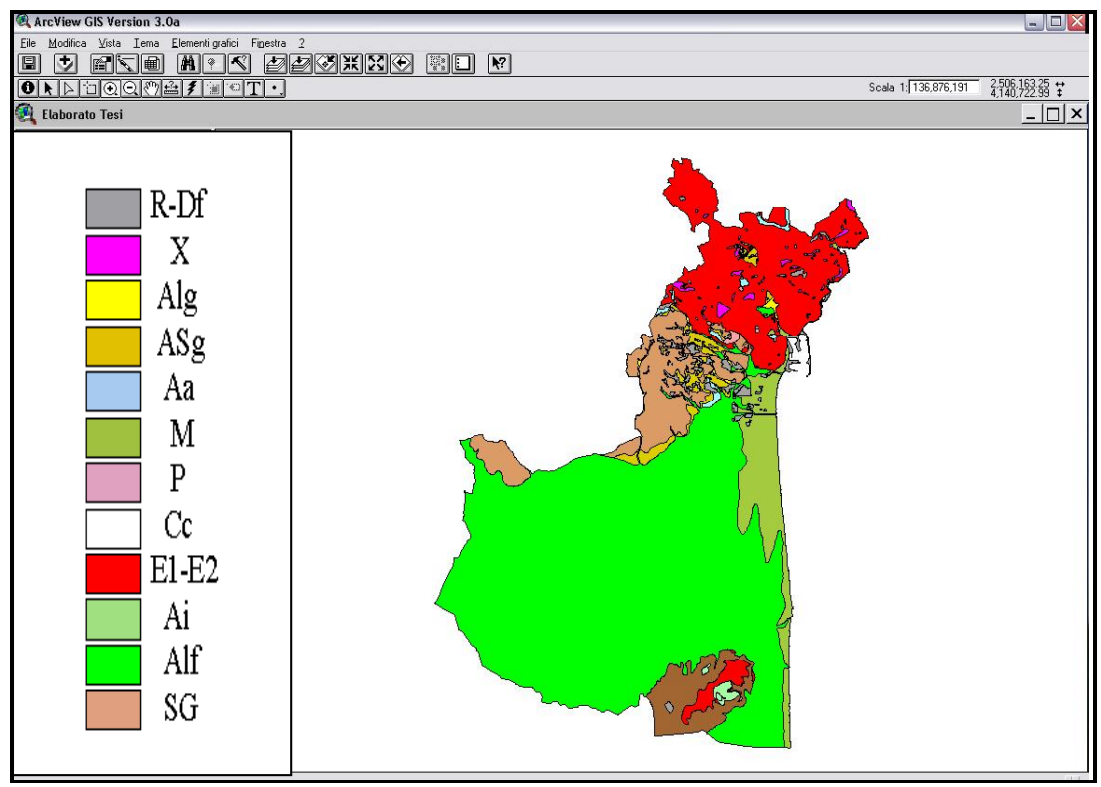

Figure 6: Schematic geo-settled geotechnical map of the city of Catania (after Pastore and Turello [6], modified). 
The location of landslide areas can be also geo-settled. Each potentially unstable slope can be analysed and geo-settled, as in the case of the Monte Po landslide, which threatened a school and some residential buildings (Grasso et al. [7]). Similar studies including not only earthquake induced landslides but also rainfall-induced landslides have been reported by Bommer and Rodriguez [8] for Central America, which is a very heavy rainfall country (Figure 7). Another factor of vulnerability of the physical environment is related to the liquefaction areas. Sand loose deposits can be located and geo-settled. Potential liquefaction can be evaluated and microzonation of potential liquefaction areas can be reported. Another factor influencing the vulnerability of the physical environment is due to the presence of cavities in the subsoil of the cities. This is common to many other Italian and Mediterranean cities. The presence of the cavities may contribute to modifying significantly the seismic action on the surface with the presence of natural and anthropic cavities or else the presence of structures within such cavities. The collapse of the vaults of these cavities represents a further factor of risk for the structures inside the cavity itself. The known cavities as an example in the city of Catania (Bonaccorso et al. [9]) have been geo-settled by the GIS system properly suited for Catania. As an example, Figure 8 shows the location and position in the GIS system of some cavities of the historic centre of Catania. Some cavities have been inspected in detail and a topographical survey was made and geo-settled, particularly for the case when the cavities were located under existing relevant buildings.

The seismic vulnerability of the urban system of Catania can also be considered as a set of relationships between built areas and void areas for connection. The prevailing causes for the exposure of the population (in each empty urban space) caused by the activities practised in the built areas can be defined.

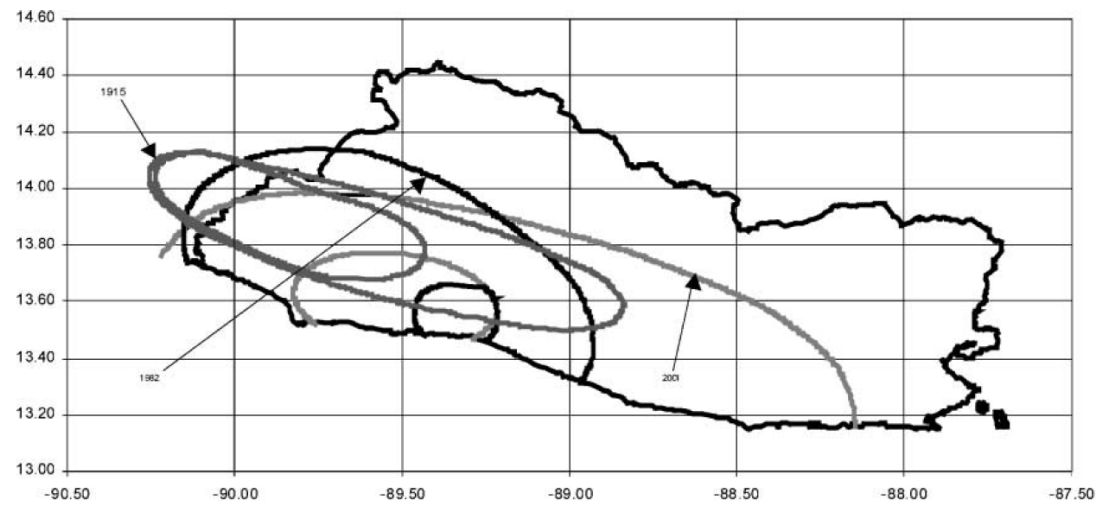

Figure 7: Areas extending to the furthest landslides and areas enclosing regions of concentrated landslides for three large-magnitude, subduction zone earthquakes in El Salvador, after Bommer and Rodriguez [8]. 


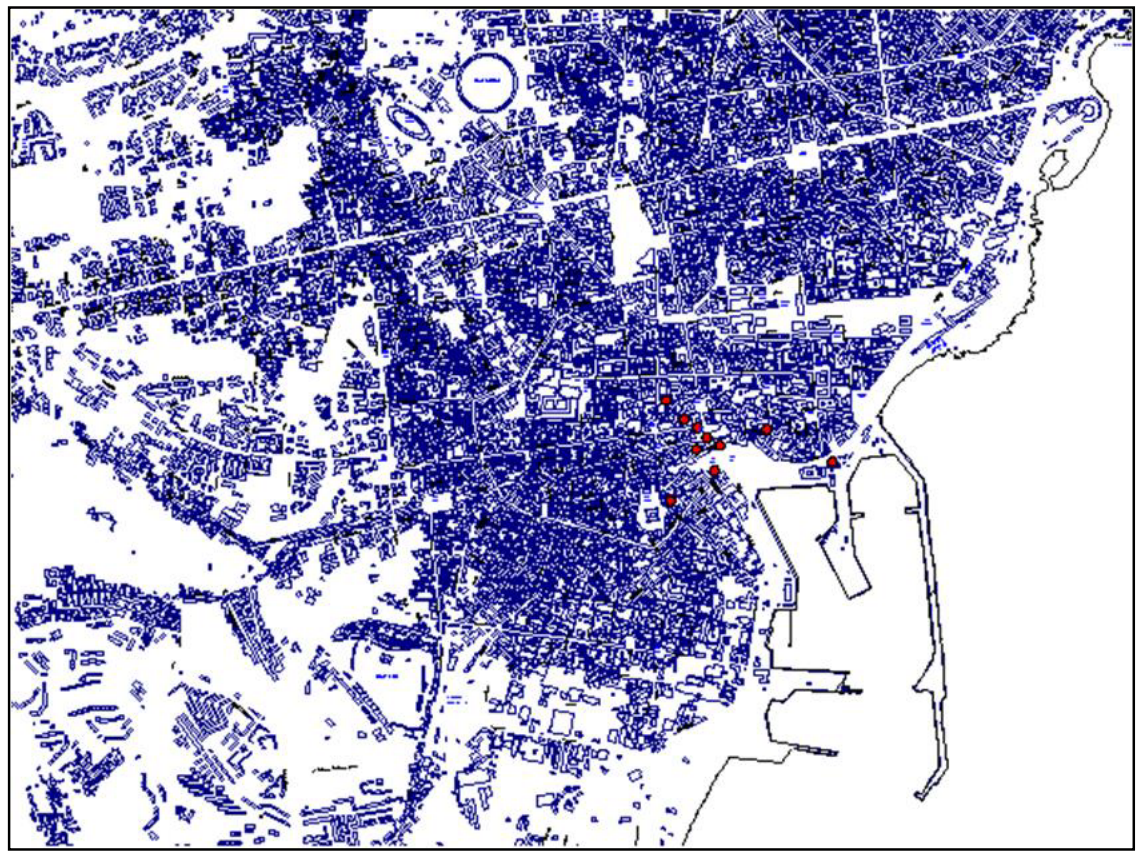

Figure 8: Location of some cavities and hypogeal structures in the historic centre of the city of Catania.

To this aim the main typologies of economic activities have been determined and specific forms of evaluation have been defined. The seismic vulnerability of urban system is also linked not only with the vulnerability of buildings but also with the functionality of road network and interruption of economic activities. Also the exposition of the population due to economic activities is considered for the evaluation of the seismic risk [10].

Some studies can be also carried out to assess the response of buried pipes to lateral ground movements with the aim to establish pipe failure risk. The analyses of soil-pipe interaction in slope with earthquake-induced movements is developed using the discrete element method to evaluate deformations and stresses in pipelines crossing unstable slopes.

The distribution of displacement, lateral deflection and bending moment along the pipe can be calculated for the prevision of unacceptable conditions for pipelines and to prevent seismic hazard in a risk analysis [10]. Seismic hazard assessment for pipelines crossing unstable slopes can be also performed [10].

\section{Vulnerability and seismic structural improvement of buildings to prevent damage}

The methodology used for the loss scenario is based on fragility curves and on vulnerability-damage-peak ground acceleration relations treated by statistical 
methods. Similar studies have been performed for Central America by Yong et al. [11], for Seattle area by MacRae et al. [12], for Chania-Greece by Anagnostopoulos et al. [13] (Figure 9) and for an urban zone of Barcelona by Barbat et al. [14]. This last work is based on the Italian vulnerability index and by the Monte Carlo method making an evaluation of damage probability matrices, fragility curves and vulnerability functions. All these studies, including those related to the Catania City and referred to the first Catania Project, could be considered as Grade-2 studies.

As an example of Grade-2 studies, Cosenza et al. [15] have been carried out the seismic assessment of two reinforced concrete buildings, representative of the most common R.C. typologies of the Catania city.

A good example of the uncertainties linked with the inventory of the stock buildings and the vulnerability assessment of each building typology is reported by Oliveira [16] in relation to the earthquake scenario for Lisbon Region.

A more detailed earthquake loss estimation has been made by D'Ayala et al. [17] surveying 200 buildings in the Alfama District of Lisbon, with reference to the 1955 Lisbon Earthquake scenario (Figure 10). Cost-benefit analysis considering only structural costs indicated that the return on the investment would be considerable.

\section{Conclusions}

A new concept has been that of considering the vulnerability of physical environment (landslides, liquefaction etc.), which play a big role on the

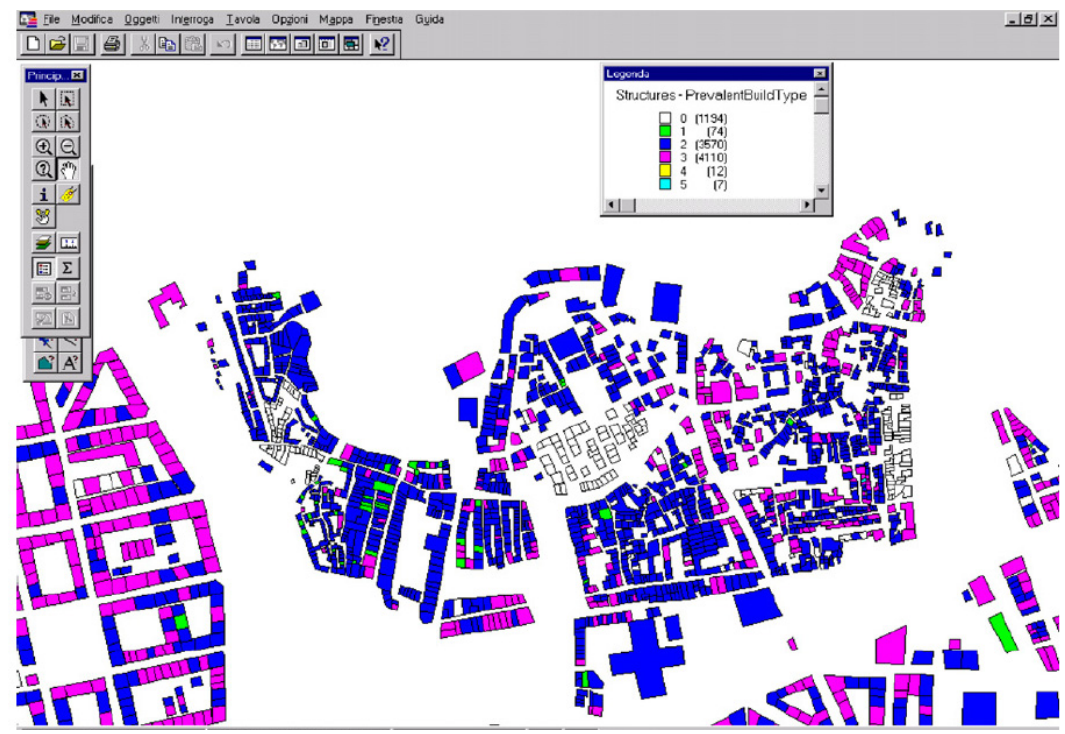

Figure 9: Building vulnerabilities of the investigated urban area of ChaniaGreece, after Anagnostopoulos et al. [13]. 


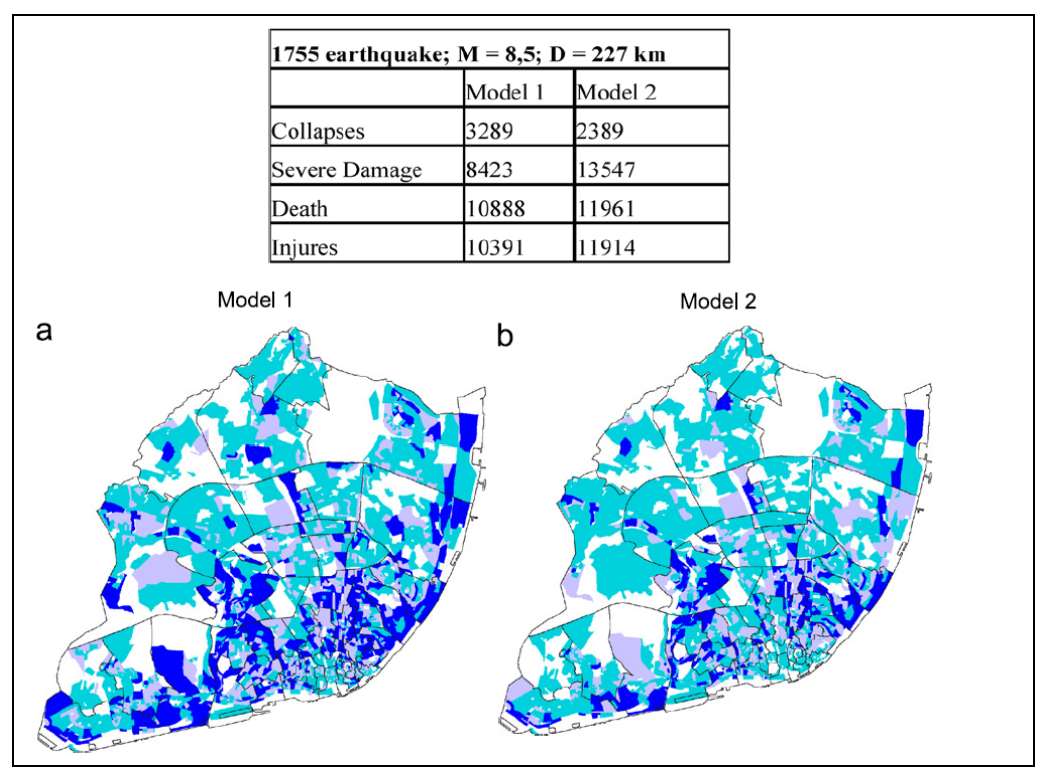

Figure 10: Influence of two different vulnerability modellings for Lisbon, after Oliveira [16]: (a) Coburn and Spence [18]; (b) Giovinazzi and Lagomarsino [19].

vulnerability of buildings, because according to EC8 the stability of foundation soil must be checked. The analysis of the vulnerability of physical environment could be a very relevant source of uncertainty.

As far as concern the vulnerability of physical environment due to landslides, innovative models have been developed in the last years. As far as concern the vulnerability of physical environment due to liquefaction, an innovative model has been developed evaluating the threshold values of pore-pressure causing permanent displacement and the threshold values of pore-pressure ratio causing failure of the slope and lateral spreading. Among the elements of vulnerability of physical environment, the peculiar presence of cavities in the cities should also be taken into account.

An innovative procedure has been developed also for the evaluation of the functionality of the road system during and after an earthquake. An innovative aspect is represented by the evaluation of the seismic vulnerability of the urban system, by the analysis of the vulnerability of urban building aggregates and the analysis of the number of population exposed to the seismic risk.

In conclusion the work has been developed methodology aspects and innovative models related to site effect evaluation, microzonation, vulnerability of physical environment evaluation (landslides, liquefaction, cavities) and vulnerability and strengthening of test buildings. 


\section{References}

[1] Cornell C.A. Engineering Seismic Risk Analysis. Bull. Seismol. Soc. Am., 1968, 58(5): 1583-1606.

[2] EERI. The Basics of Seismic Risk Analysis. Earthquake Spectra, 1989, 5(4): 675-702.

[3] Das S., Gupta D.I., Gupta V.K. A Probabilistic Seismic Hazard Analysis of Northeast India. Earthquake Spectra, 2006, 22(1): 1-27.

[4] Càceres Calix J.D. Earthquake Sources and Hazard in Northern Central America. Acta Universitatis Upsaliensis Uppsala, 2003: 1-28.

[5] Shedlock K. M. Seismic Hazard Map of North and Central America and the Caribbean. Annali di Geofisica, 1999, 42(6): 977-997.

[6] Pastore, V. \& Turello, R. (2000). Geotechnical zoning of the urban area of Catania for earthquake engineering purposes. In: The Catania Project: Earthquake Damage Scenarios for a high risk area in the Mediterranean. Editors: Faccioli and Pessina. CNR-Gruppo Nazionale per la difesa dai terremoti-Roma 2000, pp. 23-30.

[7] Grasso, S., Maugeri, M. \& Puglia, A. (2002). Sistema informativo territoriale per la zonazione del rischio di frana nel centro abitato di Catania. Atti del XXI Convegno Nazionale di Geotecnica, L’Aquila, 11-14 September 2002, pp.165-172.

[8] Bommer J.J., Rodrìguez C.E. Earthquake-induced landslides in Central America. Engineering Geology, 2002, 63: 189-220.

[9] Bonaccorso, R., Grasso, S., Lo Giudice, E. \& Maugeri, M. (2004). Cavities and hypogeal structures of the historical part of the city of Catania. In: Seismic Prevention of Damage for Mediterranean Cities. A Case History: the city of Catania (Italy). Editor M. Maugeri. WIT press, Southampton.

[10] Casamichele P., Maugeri M., Motta E., 2004. Seismic hazard assessment for pipelines crossino unstable slopes. In: Seismic Prevention of Damage for Mediterranean Cities. A Case History: the city of Catania (Italy). Editor M. Maugeri. WIT press, Southampton.

[11] Yong C., Ling C., Guendel F., Kulhanek O., Juan L. Seismic hazard and loss estimation for Central America. Natural Hazards, 2002, 25: 161-175.

[12] MacRae G.A., Ballantyne D., Stewart M., Preuss J. Seattle fault scenario A decision-making tool for earthquake risk. 2006 NZSEE Conference.

[13] Anagnostopoulos S., Providakis C., Salvaneschi P., Athanasopoulos G., Bonacina G. SEISMOCARE: an efficient GIS tool for scenario-type investigations of seismic risk of existing cities. Soil Dynamics and Earthquake Engineering, 2008, 28: 73-84.

[14] Barbat A.H., Yepez Moya F., Canas J.A. Damage scenarios simulation for seismic risk assessment in urban zone. Earthquake Spectra, 1996, 12(3): 371-394.

[15] Cosenza, E., Manfredi, G. and Verderame, G. M. Seismic assessment of gravity load designed R.C. frames: critical issues in structural modelling. Journal of Earthquake Engineering, 6, Special Issue 1: 101-122. 
[16] Oliveira C.S. Lisbon earthquake scenarios: A review on uncertainties, from earthquake source to vulnerability modelling. Soil Dynamics and Earthquake Engineering, 2008, 28: 890-913.

[17] D'Ayala D., Spence R., Oliveira C., Pomonis A. Earthquake Loss Estimation for Europe's Historic Town Centres. Earthquake Spectra, 1997, 13(4): 773-793.

[18] Coburn A, Spence R. Earthquake protection. New York: Wiley; 1992. p. 355.

[19] Giovinazzi S, Lagomarsino S. Seismic risk analysis: a method for the vulnerability assessment of built-up areas. In: Proceedings of the European Safety and reliability conference, Maastricht, 2003. 